American Journal of Applied Sciences 7 (4): 447-452, 2010

ISSN 1546-9239

(C) 2010Science Publications

\title{
Basic and Reactive Dyes Sorption Enhancement of Rice Hull through Chemical Modification
}

\author{
${ }^{1}$ Siew-Teng Ong, ${ }^{2}$ Pei-Sin Keng and ${ }^{3}$ Chnoong-Kheng Lee \\ ${ }^{1}$ Department of Chemical Science, Faculty of Science, University Tunku Abdul Rahman, \\ Jalan University, Bandar Barat, 31900 Kampar, Perak, Malaysia \\ ${ }^{2}$ Department of Pharmaceutical Chemistry, International Medical University, \\ No.126, Jalan 19/155B, Bukit Jalil, 57000 Kuala Lumpur, Malaysia \\ ${ }^{3}$ Chemical Sciences Division, Academy of Sciences Malaysia, 902-4, \\ Jalan Tun Ismail, 50480 Kuala Lumpur, Malaysia
}

\begin{abstract}
Problem statement: Many studies have been conducted on the removal of either anionic or cationic dyes. However, as a mixture of dyes does commonly exist together in wastewater, therefore it is of great interest to have a material that can remove both types of dyes. Approach: To prepare an inexpensive and efficient sorbent by chemically modifying rice hull for the removal of both basic and reactive dyes. Different chemical modifications were performed on rice hull and a comparison study on the uptake of dyes was carried out. Optimization study was carried out on most promising modified rice hull. Surface morphology of modified rice hull was examined and the functional groups present were determined using FTIR. Results: From the results, it appeared that by using EDA modified rice hull, an appreciable amount of both dyes could be sorbed. Varying the EDA/NRH ratios and heating temperatures affected the uptake of BB3 and RO16. The investigated sorbents were nonporous materials, due to the absence of pores and cavities. Sorption-desorption study showed that a complete recovery of $\mathrm{BB} 3$ can be obtained using high concentrations of $\mathrm{H}_{2} \mathrm{SO}_{4}$ and $\mathrm{HCl}$ but the desorption experiments of $\mathrm{RO} 16$ using $\mathrm{NH}_{3}$ and $\mathrm{NaOH}$ were not successful. Conclusion: The modification of rice hull with EDA under the optimum conditions (in a ratio of $1.00 \mathrm{~g}$ of NRH to 0.02 mole of EDA in a well stirred water bath at $80^{\circ} \mathrm{C}$ for $2 \mathrm{~h}$ ) resulted in the formation of a sorbent (MRH) that could be used successfully to remove Both Basic (BB3) and Reactive dyes (RO16).
\end{abstract}

Key words: Adsorption, dyes, batch study, column study, surface morphology, wastewater

\section{INTRODUCTION}

Removal of color from industrial effluents is a challenging problem in controlling environmental pollution. Textile, pulp and paper, tannery and dye manufacturing are among the most common sources of colored effluents. Various dyes used in the industry are particularly difficult to remove by conventional waste methods as they are stable to light and oxidizing agents and resistant to aerobic digestion (Low et al., 2000). There is thus a need to search for new process that could remove dyes that are commonly used in the industry. Adsorption is one of the noteworthy treatment processes. However activated carbon used as the adsorbent is costly and difficult to regenerate (Tsai et al., 2007). Thus, there has been intensive research exploring the potential of alternative low-cost materials as sorbents for dyes. A number of investigations have shown that low cost sorbents such as Neem leaf powder, hazelnut shells, rice hull and wood shavings have the potential of being used as alternative sorbent for the removal of dyes from aqueous solutions (Bhattacharyya and Sharma, 2004; Ferrero, 2006; Ong et al., 2007; 2009; Han et al., 2008; Janos et al., 2008).

Various chemical modifications on these materials have been carried out to enhance their sorption capacities and thus usefulness in the treatment of wastewater. However, most of the materials investigated are efficient in binding either cationic or anionic dyes but not both. As they do commonly exist together in wastewater it is of great interest to have a material that can remove both types of dyes.

The present project aims to modify rice hull, an agricultural by-product, to produce a material that could be used as a sorbent for both cationic and anionic dyes.

Corresponding Author: Siew-Teng Ong, Department of Chemical Science, Faculty of Science, 
In addition the surface morphology of the modified rice hull was examined using scanning electron microscope and atomic force microscopy.

\section{MATERIALS AND METHODS}

Sorbates: The cationic dye BB3 $(\mathrm{CI}=51004,40 \%$ dye content Sigma) and anionic dye RO16 (CI $=17757$, $50 \%$ dye content Aldrich) were used without further purification. Concentrations of dye solutions prepared were calculated taking the dye content into consideration. Standard dye solutions of $2000 \mathrm{mg} \mathrm{L}^{-1}$ were prepared as stock solutions and subsequently diluted when necessary.

Sorbents: For the present study, various sorbents are prepared as follows.

Natural rice hull: Rice hull was obtained from a rice mill and washed thoroughly with water to ensure the removal of dust and ash. Rice hull was then rinsed several times with distilled water and dried overnight in an oven at $50^{\circ} \mathrm{C}$. The dried rice hull was then ground to pass through a $1 \mathrm{~mm}$ sieve and labeled as Natural Rice Hull (NRH).

Base treated rice hull: Base modification was carried out by treating $2 \mathrm{~g}$ of $\mathrm{NRH}$ with $40 \mathrm{~mL}$ of $0.1 \mathrm{M}$ sodium hydroxide $(\mathrm{NaOH})$. The mixture was shaken at $300 \mathrm{rpm}$ for $1 \mathrm{~h}$ room temperature $\left(26 \pm 2^{\circ} \mathrm{C}\right)$. It was then filtered and washed with distilled water until neutral and labeled as Base treated Rice Hull (BRH).

Hydrochloric acid treated rice hull: The modification was carried out by stirring $5 \mathrm{~g}$ of NRH in $100 \mathrm{~mL}$ of $1.0 \mathrm{M}$ hydrochloric acid $(\mathrm{HCl})$ for $1 \mathrm{~h}$ at room temperature. The treated rice hull was washed with distilled water until neutral and dried overnight at $50^{\circ} \mathrm{C}$. The final product was labeled as Acid treated Rice Hull (ARH).

Quaternized rice hull: Quaternization was carried out according to the method reported by Laszlo (1996) with minor modification. About $5 \mathrm{~g}$ of NRH in $6.25 \mathrm{~mL}$ of $5 \mathrm{M} \mathrm{NaOH}$ solution was left at room temperature for $30 \mathrm{~min}$. At the end of this incubation period, 3chloro-2-hydroxypropyl trimethyl-ammonium chloride solution $\left(\mathrm{C}_{6} \mathrm{H}_{15} \mathrm{Cl}_{2} \mathrm{NO}, 65 \% \mathrm{w} / \mathrm{w}\right.$ in water $)$ with $\mathrm{pH}$ adjusted to 5.3 was added to the mixture. It was left in the oven at $60-70^{\circ} \mathrm{C}$ for $4 \mathrm{~h}$ with intermittent stirring. The reaction mixture was rinsed with distilled water and finally suspended in dilute $\mathrm{HCl}$ at $\mathrm{pH} 2$ for $30 \mathrm{~min}$. The resulting product was subsequently washed with distilled water until $\mathrm{pH}$ 5. After drying at $50^{\circ} \mathrm{C}$ overnight in the oven, it was termed Quaternized Rice Hull (QRH).

Citric acid treated rice hull: NRH was mixed with citric acid in a ratio of $1.0 \mathrm{~g}$ NRH to $7.0 \mathrm{~mL}$ of $1.2 \mathrm{M}$ citric acid. The mixture was placed in the oven at $50^{\circ} \mathrm{C}$ overnight and subsequently heated at $140^{\circ} \mathrm{C}$ for $90 \mathrm{~min}$. The reaction product was washed with distilled water until neutral and dried overnight in the oven at $50^{\circ} \mathrm{C}$. The final product was labeled as Citric Acid treated Rice Hull (CARH).

Nitrilotriacetic acid treated rice hull: Rice hull was modified in a ratio of $1.0 \mathrm{~g}$ of $\mathrm{NRH}$ to $7 \mathrm{~mL}$ of nitrilotriacetic acid. The reaction mixture was dried overnight at $50^{\circ} \mathrm{C}$. The material was subsequently heated at $140^{\circ} \mathrm{C}$ for $2 \mathrm{~h}$. Modified rice hull was then washed with distilled water until neutral and dried at $50^{\circ} \mathrm{C}$ overnight. The modified rice hull was labeled as Nitrilotriacetic acid treated Rice Hull (NTA-RH).

Ethylenediamine modified rice hull: Modification was carried out by treating NRH with Ethylenediamine (EDA). The reaction mixture was kept in a water bath at $80^{\circ} \mathrm{C}$ for $2 \mathrm{~h}$ with intermittent stirring. Optimum conditions for the treatment using EDA were determined by varying the temperature of water bath $\left(60-90^{\circ} \mathrm{C}\right)$ and the ratio of EDA (0.02-0.08 mole) to $1.00 \mathrm{~g}$ of rice hull. The reaction product was washed with distilled water until neutral, dried overnight in the oven at $50^{\circ} \mathrm{C}$ and labeled as EDA Modified Rice Hull (MRH).

Comparison study: The comparison study on the uptake of dyes by various modified rice hulls was carried out at room temperature $\left(25 \pm 2^{\circ} \mathrm{C}\right)$ by mixing $0.05 \mathrm{~g}$ of sorbent with $20.0 \mathrm{~mL}$ of dye solution in a centrifuge tube and shaken on an orbital shaker at 150 revolutions $\min ^{-1}(\mathrm{rpm})$ for $4 \mathrm{~h}$ unless otherwise stated. The reaction mixture was then centrifuged at $3000 \mathrm{rpm}$ for phase separation. All the batch experiments were carried out in duplicate and the results given are the means with a Relative Standard Deviation (RSD) of less than 5\%. Control experiments without sorbent was carried out to ascertain that the sorption was by the sorbent and not the wall of the container. The percentage of dye uptake (\% uptake) was calculated using the following equation:

$$
\text { Uptake (\%) }=\frac{\mathrm{C}_{\mathrm{o}}-\mathrm{C}_{\mathrm{t}}}{\mathrm{C}_{\mathrm{o}}} \times 100
$$

Where:

$\mathrm{C}_{\mathrm{o}}=$ The initial dye concentration

$\mathrm{C}_{\mathrm{t}}=$ The dye concentration $\left(\mathrm{mg} \mathrm{L}^{-1}\right)$ at any time 
To study the sorption-desorption process, the BB3 loaded column was eluted with 0.1 and $0.5 \mathrm{M}$ of acid solutions $\left(\mathrm{HCl}\right.$ and $\left.\mathrm{H}_{2} \mathrm{SO}_{4}\right)$, respectively, at a flow rate of $1 \mathrm{~mL}^{-1} \mathrm{~min}$. As for RO16, after the sorption process, the RO16 loaded column was eluted with $0.05-0.5 \mathrm{M}$ of $\mathrm{NaOH}$. Fifty fractions of eluants were collected at the flow rate of $1 \mathrm{~mL} \mathrm{~min}{ }^{-1}$ and analyzed for their dye concentrations. The eluted column was then washed thoroughly with distilled water to remove excess acid before being used for the next sorption/desorption cycle.

Techniques: The dye concentrations were analyzed using a Perkin Elmer Lambda 35 UV-vis spectrophotometer. All measurements were made at the wavelength corresponding to maximum absorption; for BB3, $\lambda_{\max }=654 \mathrm{~nm}$ and for RO16, $\lambda_{\max }=494 \mathrm{~nm}$. The functional groups of NRH and MRH were determined using Perkin-Elmer FTIR, $1725 \mathrm{X}$ at the wave number range of $400-4000 \mathrm{~cm}^{-1}$. The sample disk was prepared by mixing the dried biosorbent with $\mathrm{KBr}$. The mixture was then ground and compressed into a pellet before it was analyzed to obtain the spectrum. The surface morphology of NRH and MRH was studied using SEM which is equipped with energy dispersive X-ray Spectrometer (SEM-EDX)-JEOL JSM-6400 and the AFM (Quesant Q-Scope 250) which is a stylus-type instrument that scanned in raster fashion across the sample.

\section{RESULTS}

The comparative uptakes of single BB3 and RO16 by various sorbents are shown in Table 1. The optimization of modification was carried out by varying the amount of EDA used and treatment temperature. The effects of EDA/NRH ratios and heating temperatures on the uptake of BB3 and RO16 are shown in Table 2. The infrared spectra of NRH and MRH are as shown in Fig. 1. Surface morphology of

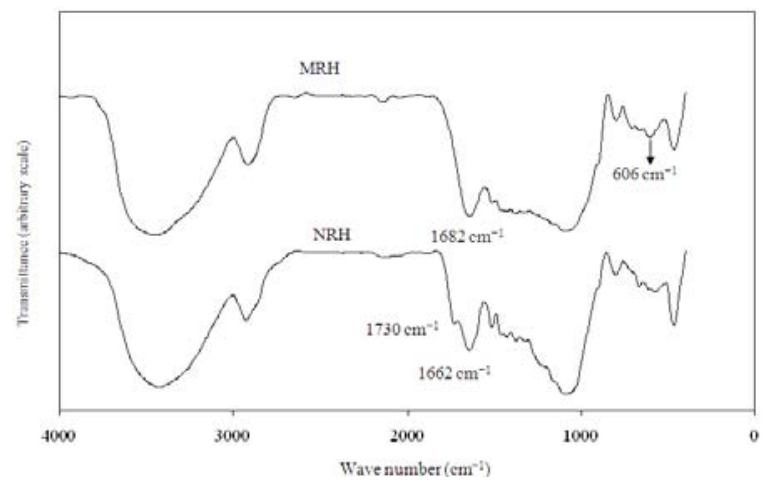

Fig. 1: Infrared spectra of NRH and MRH the sorbents studied using SEM and contact mode of AFM are presented in Fig. 2-4. Desorption characteristics of $\mathrm{BB} 3$ from single dye solution using $\mathrm{H}_{2} \mathrm{SO}_{4}$ and $\mathrm{HCl}$ at different concentrations are shown in Fig. 5 and 6 , respectively.

Table 1: Uptake of dyes by chemically modified rice hull

\begin{tabular}{lcr}
\hline & Uptake (\%) & \\
Sorbent & BB3 & RO16 \\
\hline NRH & 24.44 & 0.37 \\
BRH & 15.01 & 5.97 \\
ARH & 0.52 & 15.37 \\
QRH & 1.11 & 10.78 \\
CARH & 26.45 & 0.76 \\
NTA-RH & 14.18 & 0.15 \\
MRH & 9.53 & 32.44 \\
\hline
\end{tabular}

Condition: $0.05 \mathrm{~g}$ of sorbent was shaken with $20 \mathrm{~mL}$ of dye solution $\left(100 \mathrm{mg} \mathrm{L}^{-1}\right)$ at an agitation rate of $150 \mathrm{rpm}$ for $4 \mathrm{~h}$ at room temperature

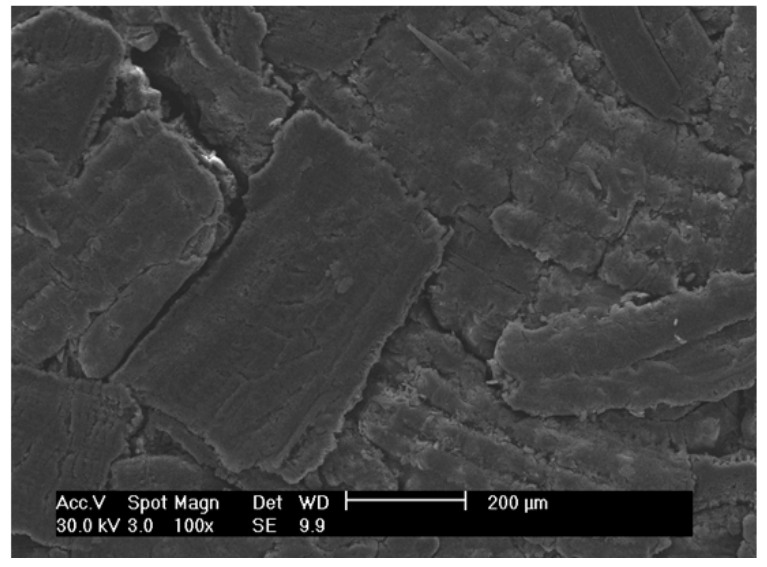

Fig. 2: SEM micrograph of NRH

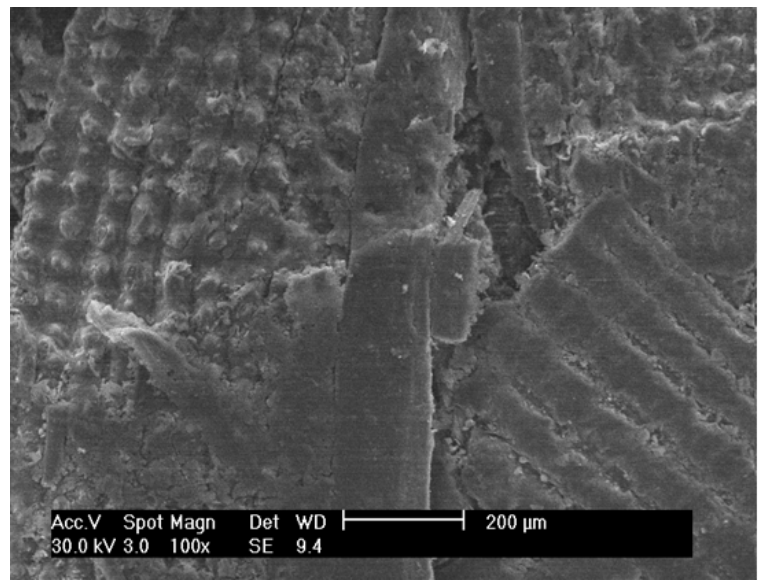

Fig. 3: SEM micrograph of MRH 
Am. J. Applied Sci., 7 (4): 447-452, 2010

Table 2: Uptake of dyes by MRH at various treatment temperatures and EDA concentrations for $2 \mathrm{~h}$

\begin{tabular}{|c|c|c|c|c|c|c|c|c|}
\hline \multirow{4}{*}{$\begin{array}{l}\text { Ratio of EDA } \\
\text { (mole): } \\
1 \mathrm{~g} \text { rice hull }\end{array}$} & \multicolumn{8}{|c|}{ Uptake (\%) } \\
\hline & \multicolumn{4}{|c|}{ Basic blue 3} & \multicolumn{4}{|c|}{ Reactive orange 16} \\
\hline & \multicolumn{8}{|c|}{ Treatment temperature $\left({ }^{\circ} \mathrm{C}\right)$} \\
\hline & 60 & 70 & 80 & 90 & 60 & 70 & 80 & 90 \\
\hline & 28.39 & 26.86 & 25.42 & 22.99 & $\begin{array}{l}50.83 \\
\end{array}$ & 56.74 & 63.44 & 64.23 \\
\hline 0.015 & 28.24 & 26.16 & 24.56 & 22.18 & 55.44 & 58.68 & 60.08 & 63.77 \\
\hline 0.02 & 28.71 & 26.31 & 24.64 & 22.07 & 55.92 & 57.95 & 64.23 & 63.87 \\
\hline 0.025 & 28.04 & 24.32 & 22.91 & 22.40 & 52.19 & 57.61 & 64.06 & 63.77 \\
\hline 0.03 & 28.14 & 24.12 & 22.01 & 21.01 & 51.67 & 56.03 & 59.25 & 60.20 \\
\hline 0.04 & 25.45 & 22.30 & 20.91 & 20.30 & 49.82 & 54.67 & 55.87 & 45.80 \\
\hline
\end{tabular}

Condition: $0.1 \mathrm{~g}$ of sorbent was shaken with $20 \mathrm{~mL}$ dye solution $\left(100 \mathrm{mg} \mathrm{L}^{-1}\right)$ at an agitation rate of $150 \mathrm{rpm}$ for $4 \mathrm{~h}$ at room temperature

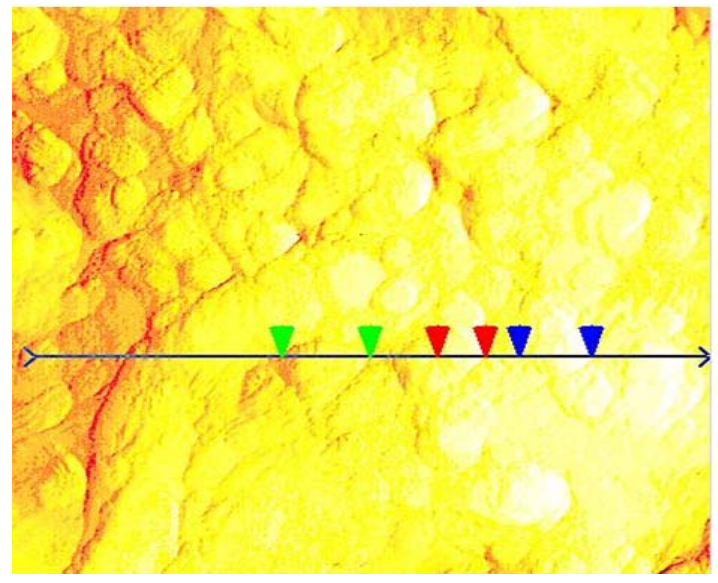

Fig. 4: AFM image of MRH with transect line for cross-sectional analysis

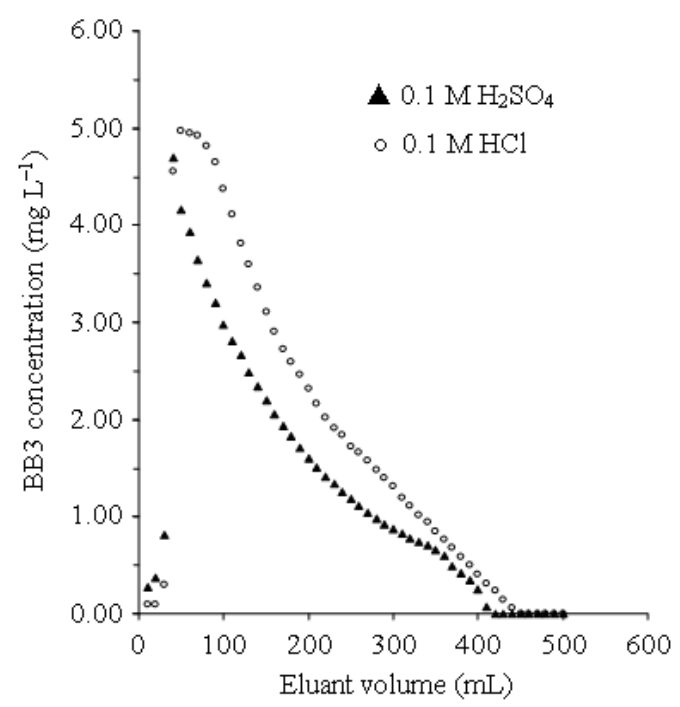

Fig. 5: Elution process of $\mathrm{BB} 3$ from single dye solutions in $\mathrm{MRH}$ column using $0.5 \mathrm{M} \mathrm{H}_{2} \mathrm{SO}_{4}$ and $0.5 \mathrm{M} \mathrm{HCl}$

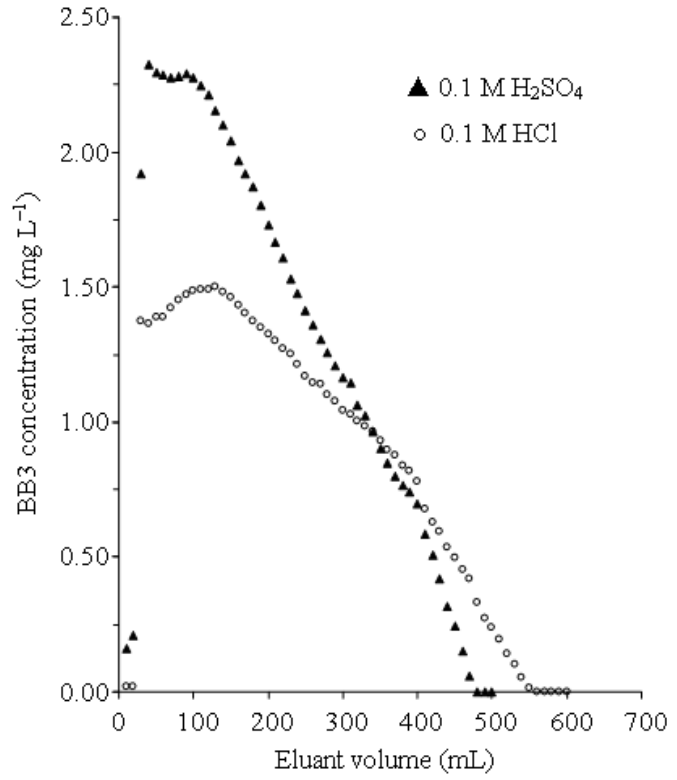

Fig. 6: Elution process of $\mathrm{BB} 3$ from single dye solutions in $\mathrm{MRH}$ column using $0.1 \mathrm{M} \mathrm{H}_{2} \mathrm{SO}_{4}$ and $0.1 \mathrm{M} \mathrm{HCl}$

\section{DISCUSSION}

Comparison study on the dyes uptake: From the results, it appears that by using $\mathrm{MRH}$ as a sorbent, an appreciable amount of both dyes could be sorbed. Since the objective of this study is to find a material that can remove both types of dyes simultaneously, subsequent studies were carried out using MRH.

Optimization of modification of rice hull using ethylenediamine: The results show that sorption of BB3 decreased with increasing reaction temperature while the sorption of RO16 showed the opposite trend. Increasing reaction temperature would probably enhance the introduction of amine groups which are responsible for 
the sorption of anionic species onto the rice hull. Amination involved carboxyl groups on the rice hull, thereby decrease the availability of carboxyl groups that binds BB3.

Varying EDA/NRH ratio indicates that sorption of BB3 and RO16 generally increased as the ratio increased and then decreased. This can be related to the more alkaline condition that brings about changes in the rice hull structure, thus resulting in lower sorption capability. Bai and Abraham (2001) reported that excess alkali treatment caused drastic effects like swelling of biomass, probably due to polymer chain breakage thereby hindered the operational stability. In this study, modification was therefore optimized at treating rice hull with EDA in a ratio of $1.00 \mathrm{~g}$ rice hull to 0.02 mole of EDA in a well stirred water bath at $80^{\circ} \mathrm{C}$ for $2 \mathrm{~h}$.

Fourier-transform infrared spectroscopy: Generally, the functional groups present in NRH and MRH cannot be clearly differentiated. Absorption in the region 3200$3600 \mathrm{~cm}^{-1}$ is from $\mathrm{OH}$ stretching vibrations. The absorption of the $\mathrm{OH}$ group does not usually appear as a sharp peak, instead a broad band is observed because the vibrational mode is complicated by hydrogen bonding. The modification of NRH using EDA yields primary amine groups on MRH. Therefore, peaks in the region of $3444 \mathrm{~cm}^{-1}$ in $\mathrm{MRH}$ could be indicative of both N-H stretching $\left(3000-3600 \mathrm{~cm}^{-1}\right)$ and $\mathrm{OH}$ that occur at almost the same region. The presence of $\mathrm{N}-\mathrm{H}$ bands plus an unusually low value for the $\mathrm{C}=\mathrm{O}$ (stretch occurs at approximately $1680-1630 \mathrm{~cm}^{-1}$ ) would suggest the presence of an amide functional group. Primary amides also show a broad band from 750$600 \mathrm{~cm}^{-1}$. Thus, the absorption band shown at 1682 and $606 \mathrm{~cm}^{-1}$ in MRH spectra may be attributed to amide functional groups. The absorption band of $1730 \mathrm{~cm}^{-1}$ observed in infrared spectra of $\mathrm{NRH}$ is due to $\mathrm{C}=\mathrm{O}$ group of carboxylic acid. Both $\mathrm{NRH}$ and $\mathrm{MRH}$ illustrate a similar peak around $2900 \mathrm{~cm}^{-1}$ and this is owing to $\mathrm{C}-\mathrm{H}$ stretching.

Scanning electron microscopy: From the SEM micrographs, it is observed that there was little difference between NRH and MRH surface morphology. This is because modification using EDA involved only the introduction of amine groups on the surface of rice hull but the fibrous network of the rice hull was retained. It is also clear that all the investigated sorbents are non-porous materials, due to the absence of pores and cavities.

Atomic force microscope: The surface morphology of MRH (Fig. 4) measured using the contact mode by
AFM on a $20 \times 20 \mu \mathrm{m}^{2}$ area was carried out to provide information on the cross-section analysis, bearing analysis and roughness analysis. Both NRH and MRH exhibit spherical like structures and the section analysis obtained through the selection of the transect line across the sample shows that the grain size in NRH has a broad distribution ranging from 0.718-2.364 $\mu \mathrm{m}$ whereas $\mathrm{MRH}$ exhibits a smaller range, 1.370-2.085 $\mu \mathrm{m}$. The AFM image when analyzed in terms of average surface roughness $\left(\mathrm{R}_{\mathrm{a}}\right)$, increases from $169.5 \mathrm{~nm}(\mathrm{NRH})$ to $330.0 \mathrm{~nm}$ in MRH. This is most probably caused by the eruption during EDA modification.

Sorption and desorption: In regeneration, the choice of eluant should be considered in terms of desorption efficiency and preservation of biocapacity of the sorbent. In order to evaluate the feasibility of using MRH for multiple sorption cycles, sorption and desorption processes were carried out. The results show that a complete recovery of $\mathrm{BB} 3$ can be obtained using high concentrations of $\mathrm{H}_{2} \mathrm{SO}_{4}$ and $\mathrm{HCl}$ (Fig. 5). With $0.1 \mathrm{M} \mathrm{H}_{2} \mathrm{SO}_{4}$ and $\mathrm{HCl}$ only 46.5 and $30 \%$ recovery, respectively can be achieved (Fig. 6). In general, the extent of BB3 desorption increases with the increase in the strength of acids from 0.1-0.5 M. Besides, faster desorption was noted in the case of $\mathrm{H}_{2} \mathrm{SO}_{4}$. This can be related to the stronger acidity of $\mathrm{H}_{2} \mathrm{SO}_{4}\left(\mathrm{pK}_{\mathrm{a}}=-10\right)$ compared to $\mathrm{HCl}\left(\mathrm{pK}_{\mathrm{a}}=-7\right)$. The stronger acid has a greater tendency to give up its proton. The introduction of acids into BB3 loaded column protonates the functional groups that are responsible for the binding of BB3 thereby displacing BB3. However, desorption of BB3 carried out with acid solutions introduces negative effect on the reuse of the MRH column. The MRH column cannot be reused, probably due to the saturation of the binding sites with $\mathrm{H}^{+}$ions during the desorption process. Calace et al. (2003) found that $\mathrm{HCl}$ can be used in the recovery of $\mathrm{Cu}^{2+}$ and $\mathrm{Cd}^{2+}$ from paper mill sludge column but the eluting process caused the sorbing sites to be saturated with hydrogen ions, thus hindered it from repeated usage.

The desorption experiments of $\mathrm{RO} 16$ using $\mathrm{NH}_{3}$ and $\mathrm{NaOH}$ were not successful. This can be related to the strong electrostatic attraction between RO16 and sorbent as well as the occurrence of dipole-dipole interaction. From the dye structure of RO16, it is clear that it consists of many polar groups. Thus, the attraction between these polar groups should be taken into consideration as the dipole-dipole interaction increases with an increase in the polarity of the molecule.

\section{CONCLUSION}

The present study shows that modification of rice hull with EDA under the optimum conditions (in a 
ratio of $1.00 \mathrm{~g}$ of NRH to 0.02 mole of EDA in a well stirred water bath at $80^{\circ} \mathrm{C}$ for $2 \mathrm{~h}$ ) resulted in the formation of a sorbent (MRH) that could be used successfully to remove Both Basic (BB3) and Reactive dyes (RO16). The functional groups present before and after modifications cannot be clearly distinguished through the infrared spectra obtained and this could be due to the limitations in the sensitivity of the instrument. The surface morphology of the sorbent was studied using SEM and AFM. Results show that all the investigated sorbents are non-porous materials. In sorption-desorption study, a complete recovery of $\mathrm{BB} 3$ can be obtained by eluting the saturated column with $0.5 \mathrm{M} \mathrm{H}_{2} \mathrm{SO}_{4}$ and $0.5 \mathrm{M}$ $\mathrm{HCl}$ but the column cannot be reused. The desorption of $\mathrm{RO} 16$ using $\mathrm{NaOH}$ and $\mathrm{NH}_{3}$ was not successful and this could be due to the strong electrostatic attractions as well as the occurrence of hydrogen bonding.

\section{ACKNOWLEDGEMENT}

Financial support from the International Foundation of Science, Stockholm, Sweden and the Organization for the prohibition of chemical weapons, The Hague, The Netherlands via grant no. W/4368-1 as well as the lab facilities provided by University Tunku Abdul Rahman (UTAR) is acknowledged.

\section{REFERENCES}

Bai, S.R. and T.E. Abraham, 2001. Biosorption of $\mathrm{Cr}$ (VI) from aqueous solution by Rhisopus nigricans. Bioresource Technol., 79: 73-81. DOI: 101016/S0960-8524(00)00107-3

Bhattacharyya, K.G. and A. Sharma, 2004. Kinetics and thermodynamics of methylene Blue adsorption on Neem (Azadirachta indica) leaf powder. Dyes Pigm., 65: 51-59. 10.1016/j.dyepig.2004.06.016

Calace, N., E. Nardi, B.M. Petronio, M. Pietroletti and G. Tosti, 2003. Metal ion removal from water by sorption on paper mill sludge. Chemosphere, 51: 797-803. DOI: 10-1016/S0045-6535(02)00864-0
Ferrero, F., 2006. Dye removal by low cost adsorbents: Hazelnut shells in comparison with sawdust. J. Hazard. Mater., 142: 144-152. DOI: 10.1016/j.jhazmat.2006.07.072

Han, R.P., D.D. Ding, Y.F. Xu, W.H. Zou and Y.F. Wang et al., 2008. Use of rice husk for the adsorption of Congo red from aqueous solution in column mode. Bioresource Technol., 99: 29382946. DOI: 10.1016/j.biortech.2007.06.027

Janos, P., S. Coskun, V. Pilarova and J. Rejnek, 2008. Removal of basic (methylene blue) and acid (egacid orange) dyes from waters by sorption on chemically treated wood shavings. Bioresource Technol., 100: 1450-1453. DOI: 10.1016/j.biortech.2008.06.069

Laszlo, J.A., 1996. Preparing an ion exchange resin from sugarcane bagasse to remove reactive dye from wastewater. Text Chem. Color, 28: 13-17.

Low, K.S., C.K. Lee and B.F. Tan, 2000. Quarternized wood as sorbent for reactive dyes. Applied. Biochem. Biotechnol., 87: 233-245. DOI: 10.1385/ABAB:87:3:233

Ong, S.T., C.K. Lee and Z. Zainal, 2007. Removal of basic and reactive dyes using ethylenediamine modified rice hull. Bioresource Technol., 98: 27922799. DOI: 10.1016/j.biortech.2006.05.011

Ong, S.T., E.H. Tay, S.T. Ha, W.N. Lee and P.S. Keng, 2009. Equilibrium and continuous flow studies on the sorption of Congo red using ethylenediamine modified rice hulls. Int. J. Phys. Sci., 4: 683-690. http://www.academicjournals.org/IJPS/abstracts/abst racts/abstracts2009/November/Ong\%20et\%20al.htm

Tsai, W.T., H.C. Hsu, T.Y. Su, K.Y. Lin and C.M. Lin, 2007. Removal of basic dye (methylene blue) from wastewaters utilizing beer brewery waste. J. Hazard. Mater., 154: 73-78. DOI: 10.1016/j.jhazmat.2007.09.107 